\title{
The Columbia Building Intelligence Project
}

SCOTT MARBLE

Columbia University
In a short editorial in Wired Magazine just after the Crash of 2008, "The New Economy: More Startups, Fewer Giants, Infinite Opportunity", Chris Anderson suggested that what led up to the latest economic crash was not just another dip in the ebb and flow of reliable past economic cycles, but rather the last gasp of big-business models that were struggling to adapt to the new pace of change. They were being challenged by more agile, creative and innovative small firms with new models of scalability that would allow them to be competitive in large markets. This was not to say that large firms in all business sectors would cease to exist, but it did hint at a trend that has only accelerated since this claim was made 7 years ago; that much of the innovation and new ideas that are making big changes and disruptive shifts in how industries operate are being generated from small start-up firms. This is being largely facilitated by how these firms leverage digital communication technologies as the foundation of their business models along with their full embrace of a new social and cultural dynamic that in only 10 years has developed into an entirely new structure for the exchange of goods and services referred to as the Sharing Economy.

What does this mean for the architecture, engineering and construction (AEC) Industry and architectural education in particular? Architectural education used to be about preparing students to proceed with their internship upon graduation in preparation for professional registration and a stable job in an architectural firm. No more. There are indications that business as usual is getting short circuited by an impatient, eager, tech-savvy and network-minded generation who see alternative career tracks that are faster, more interesting, and capable of having a greater impact on industry. This new attitude is partly due to the memory of the recent economic slump and challenging job market that awaited recent graduates, but it is also the result of a hunch that this generation has that the future design and construction industry can and should be much different than it is now. The entrenched silo structure of the current AEC industry that continues to undermine the sharing of information and ideas that is the foundation of meaningful collaboration among architects, engineers, fabricators and contractors, seems alien to a new generation who grew up with the open information exchange of the internet and who see sharing as a natural way to gain knowledge and be productive. 


\section{THE COLUMBIA BUILDING INTELLIGENCE PROJECT (C BIP)}

This hunch was at the core of the Columbia Building Intelligence Project (C BIP), which was launched at the Graduate School of Architecture, Planning and Preservation (GSAPP) at Columbia University in the fall of 2009. C BIP was initiated as a 3-year pilot research project designed to explore new forms of technology-enabled collaboration within and between the various sectors of the architecture, engineering, and construction (AEC) industry. The project grew out of an interest in using emerging digital design and communication technologies and the increasing trends toward more integrated forms of practice to address the entrenched adversarial atmosphere that has inhibited the progress of our industry for many years. In addition, C-BIP was based on the premise that changing the future of our industry depends on transforming the education of our future leaders, which begins with a renewed engagement between academia and industry.

C BIP was comprised of local and international Think Tanks and the C BIP Studio. The Think Tanks brought together leading industry experts including architects, engineers, builders, owners, fabricators, research scientists, software developers and educators in an open dialogue about current projects, working processes and research that form the most technologically progressive industry practices. Each year, one of Think Tanks was held in New York and was more directly related to the work of the C BIP Studio allowing an exchange of ideas between GSAPP students, faculty and the Think Tank participants. In response to the global dynamics of the AEC industry, the other Think Tanks took place in major regional centers around the world to better understand how the topics around design, technology and collaboration shift in different cultural and economic contexts. The Think Tanks uncovered key questions and issues that established a broad foundation to position and evolve the C BIP Studio.

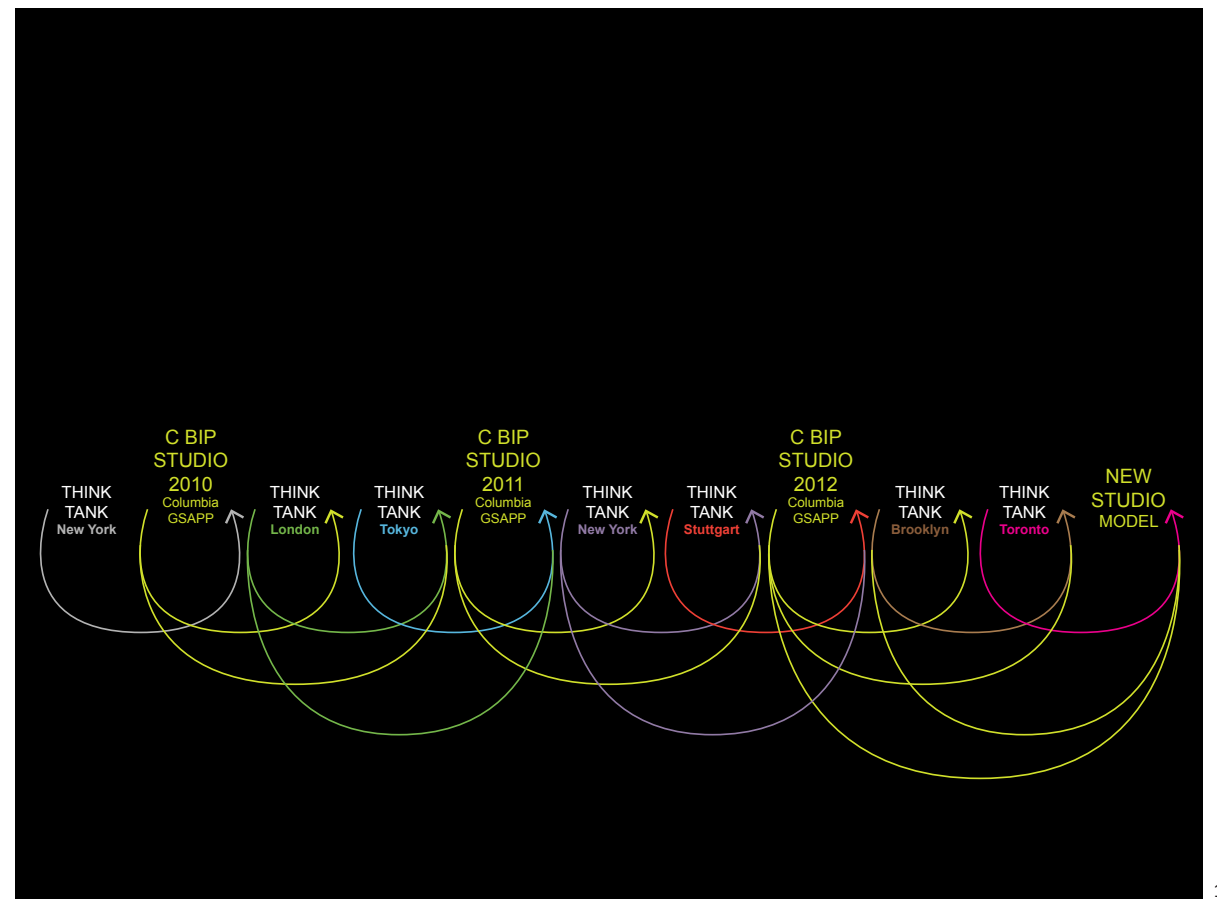

The C BIP Studio was the anchor of The Columbia Building Intelligence Project, which was conceived as a new studio model that responded to the increasing complexity of contemporary design problems. As an evolution of the typical studio model of 12 students working on individual projects and guided by a single instructor, the C BIP Studio was a highly integrated model where 36 students worked interactively on specific parts of a larger problem, guided by three critics and several technical consultants and guest advisers from industry 
who served as experts on key issues relating to the studio topic. The primary objective of this new structure was to encourage the sharing of information, the open exchange of ideas and a deep understanding among the students of the potential of collective teamwork. The students produced design work that was shared and combined through structured parametric modeling allowing the individual work of each student to contribute to the entire studio. The C BIP Studio took place in the fourth semester of the Master of Architecture Program when students transition from core to advanced studios. At this point in their education, students had enough background to make informed contributions to a team project while also having another year after completing C BIP to integrate their new findings into future work at the GSAPP.

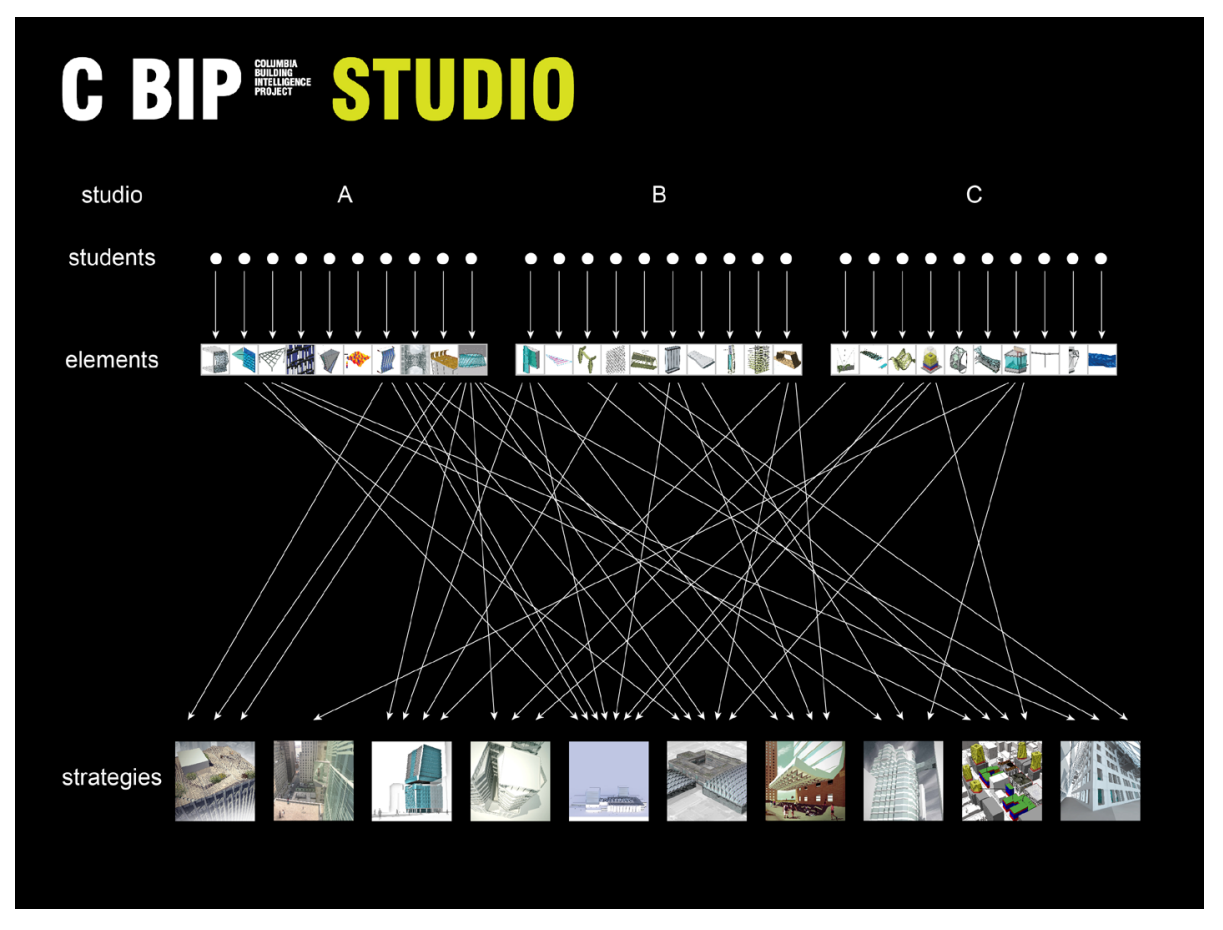

\section{THE STATE OF INDUSTRY - THE CONTEXT FOR C BIP}

The practice of architecture has always been about managing information. Architects produce drawings that coordinate the efforts of multiple constituents with the goal of producing buildings. However, the amount of relevant and available information that is useful for any given architectural project today has expanded faster than the development of integrated and synthetic working methods. The amount of expertise required to design, fabricate and construct a new building has lead to multidisciplinary teams that expand far beyond the traditional architect, engineer, and contractor model. This has simultaneously led to more collaboration between individual people, specialized teams, and a fragmentation of information that often inhibits the full benefits of a collective workflow. This is largely due to the lack of effective means to organize and coordinate the efforts of the multiple team members. While this is certainly a logistics issue, it is also a design issue in that any organizational system has inherent biases that either support or obstruct the potential of creative work.

With the availability of ubiquitous digital communication technologies, the rapid transformation of industry through these technologies, and a new entrepreneurial spirit among a younger generation, architects are now able to leverage their position so that they have the potential to design the organization of a project-to creatively and strategically assemble new alliances and relationships among owners, clients, builders, fabricators, consultants, 
etc. that lay the groundwork for innovative architecture. The C BIP Studio addressed this new working environment with the goal of preparing the next generation of architects to lead in the development of new modes of practice.

Acknowledging that industry is already moving toward a restructuring with new developments like Building Information Modeling (BIM) and Integrated Project Delivery (IPD), which promise to address many of the procedural inefficiencies in design and construction, C-BIP attempted to build on this restructuring while also critically addressing some of the difficult questions beginning to emerge for architects. For example, what is the relationship between BIM and design? At what point does the degree of integration that is the basis of both BIM and IPD become a deterrent for design, innovation, and risk taking (which goes hand in hand with innovation)? Is the degree of integration inversely proportionate to the degree of flexibility for more open-ended design? Are BIM and IPD only for managing workflow or can they evolve to support more effective design methodologies?

One aspect of the studio methodology borrowed from the concepts of collective intelligence and how it might be applied to architecture. As individual projects evolve to include more and more information, as well as more and more stakeholders, how might diverse and decentralized groups make intelligent design decisions? In architecture, is it possible to leverage "the wisdom of crowds," as theorized by business writer James Surowiecki? ${ }^{1}$ Is there a way for design teams to take advantage of "crowd sourcing," the contribution of many distributed users toward a collective product?

Another aspect explored how open source-a design method pioneered for software development-might be reformulated for architectural design and how multiple independent parties might build successive versions of a part toward the goal of a single deliverable. ${ }^{2}$ Could modules of buildings and 3D files be "checked out," revised, and "checked in" by different architects, fabricators, and contractors over time durations that exceed a single project? How would discrepancies between versions be handled? If complex building parts could be designed, documented, and released into a broad architectural community, how would intellectual property be handled? Might an open source model start to change the one-off nature of buildings and reduce inefficiencies in the construction industry?

The C BIP Studio also explored how cooperation and sharing could change the process of design to realign the motivations and incentives that drive design decisions. ${ }^{3}$ Shared risk, shared reward is a cooperative structure at the core of Integrated Project Delivery (IPD) intended to align the priorities between design teams, contractors and owners around financial incentives. This structure is less beneficial for architects due to the value of their services, in financial terms, in relation to overall project costs. What other value structures could encourage people to move towards collaborative work? Can the silo structure that defines current practice be overcome in a highly litigious working environment? If so, how can the next generation accomplish this and put legal structures at the service of design instead of vise versa. Can the next generation transfer the deeply rooted culture of sharing that defines their daily social life into a sustainable business model for design?

The C BIP Studio engaged these more speculative questions backed with an understanding of the current state of industry to develop new design workflows that might contribute to meaningful change to the practice of architecture and its future position within the AEC industry.

\section{ENERGY + ADAPTATION, THE C BIP PROGRAM}

Cities around the world have begun developing ambitious programs with specific goals and timeframes to make tangible progress in addressing global climate change. As one example, PlaNYC was initiated in 2007 with the target of reducing carbon-dioxide emissions in New 
York City by $30 \%$ by the year 2030 . Because of the density of NYC, buildings make up $75 \%$ of the city's overall carbon emissions. The advances made in high performance design and engineering will keep new buildings from compounding this problem. However, $85 \%$ of the buildings that will exist in NYC in the year 2030 already exist today so, as in most cities, the greater challenge is not the design of new buildings but how to adapt the existing building stock to current standards. This challenge was the program topic of research for the C BIP Studio.

As a systematic approach to addressing energy mitigation and in order to address the greatest number of low performing buildings in the city, representative building types were determined through an urban analysis using numerous relational data sets and parameters taken from the PlaNYC program. These parameters included buildings larger than 50,000 square feet (SF) and buildings built before 1990, the time period when energy performance became a more important design concern. This analysis resulted in six building types that collectively represented just over $37 \%$ of the total building SF in New York City, but more importantly, these 6 types represented $87 \%$ of the building SF of buildings within our targeted building profile. These types included glass towers, schools, lofts, mid-rise residential, high-rise residential and public housing. A representative building was chosen from each of these types as a case study site for the studio.

Much of the building adaptation work to address energy mitigation occurs with little or no architectural or urban effect - upgrading building systems, increased insulation on perimeter walls, window replacement, etc. Students were made aware of this but were also asked to explore how to leverage the resources that would be dedicated to this effort to design adaptation strategies that would affect the urban landscape. The following environmental metrics were used to direct this effort: increased daylighting, reduced heat gain or heat loss, quantity of water stored and re-used, change in vegetated area, electricity or solar heat generated, improved ventilation and reduction in construction waste.

\section{DESIGN \& RELEASE - THE C BIP STUDIO WORKFLOW}

Unlike a typical studio in which students work alone and produce one-off designs, the $C$ BIP Studio employed a design-and-release model based on sharing. Over the course of the semester, each student authored a building Element (addressing a building part) that would be combined with Elements authored by other students to create a building Strategy (addressing an entire building). A single student designed the Elements in the first phase of the semester and the Strategies were designed by a group of 3-5 students in the second phase. As the semester progressed, students would be simultaneously refining the design of their Elements while also working in a group to develop a Strategy.

For the design of their Elements and Strategies, students utilized design, analysis and production software currently used by the building industry for its most advanced projects. Taking advantage of the unique opportunities of academia, students explored BIM practices and parametric modeling techniques in novel and experimental ways to contribute to the broader research and development of new integrated and collaborative design workflows. The core software of the studio workflow was CATIA, a powerful parametric modeling platform originally developed for design and manufacturing in the aerospace industries by large distributed teams of engineers and now being used to design and construct complex architecture projects.

In addition to the 3 design critics, the teaching team consisted of several technical experts from local architecture, engineering and consulting firms who developed and managed the digital workflow for the studio. These outside consultants also brought industry expertise in other areas including architectural detailing, structural engineering, environmental 
engineering and software interoperability. Over the course of the semester, students became fluent in CATIA as the common platform for structuring the exchange of design ideas with others in the studio through shared parametric models. Students also learned to use SVN (a version-control system for managing and sharing current and past versions of files), SBA (an arbitration system for resolving conflicts in design goals), along with multiple methods for building simulation (including finite element analysis, computational fluid dynamics, and environmental analysis) for evaluating the performance of design iterations. By utilizing these new advanced modeling tools and structured design workflows students were able to create robust, adaptive parametric models that set the foundation for the most important objective of the C BIP studio - sharing design intelligence

\section{PHASE 1: ELEMENTS}

Elements were designed by each student in CATIA in response to their research on energy use and the particular NYC building type selected as a site. In this first phase, Elements were designed as prototypical based on generic building conditions with maximum flexibility to adapt to more specific building conditions during the Strategy phase. The studio took two approaches toward energy-related building adaptation: the mitigation of energy use and the harvesting of energy. To focus the work students chose one of three building conditions to address: facades, roofs, and courtyards. Beginning with the design of generic building components, the students adapted their designs to each other's and to a series of selected buildings, urban conditions, infrastructures, and scales. The goal was to invent architectural solutions to energy mitigation and harvesting in existing buildings that were at once speculative, experimental, innovative and technically feasible. [IMAGE 3: SAMPLE ELEMENT]

As parametric models, Elements were structured with specific inputs and outputs that were an essential part of the author's design intent. Inputs had to give users sufficient flexibility to explore many design options without being too open-ended. Outputs had to provide users with useful information to be able to assess results. Outputs consisted of both geometry (visual images that architects typically use to qualitatively evaluate results) and numbers (metrics that give quantitative aspects of the results).

In anticipation of phase 2 where Elements would be combined to form integrated Strategies, students (as Element authors) were asked to exchange early versions of their Element design with at least 2 other students (Element users) to get feedback on usability and overall design capacity. Users were encouraged test the limits of the Elements to get unexpected outputs and even to "break" the Elements if possible. This step proved valuable in making sure the Elements were designed to be robust and in providing authors with new ideas about how to expand the functionality of their designs. As part of the exchange, students were also required to combine two Elements together where the numeric outputs from one served as the inputs to another. This was the initial step in understanding how Elements could link together to form a Strategy. It also emphasized the point that by definition, Elements should be conceived as "incomplete" and reliant upon other Elements to realize greater design potential.

At the conclusion of this phase, v1 Elements were packaged and uploaded into an Element Library for use in the next phase. These early versions became referred to as "low-res" and often emphasized the overall functionality to generate useful numeric outputs over fully developed geometry with the understanding that users would want more control over geometry and appearance. User guides were attached to each Element explaining the authors design intent and providing users with step-by-step instructions on using inputs and outputs. 


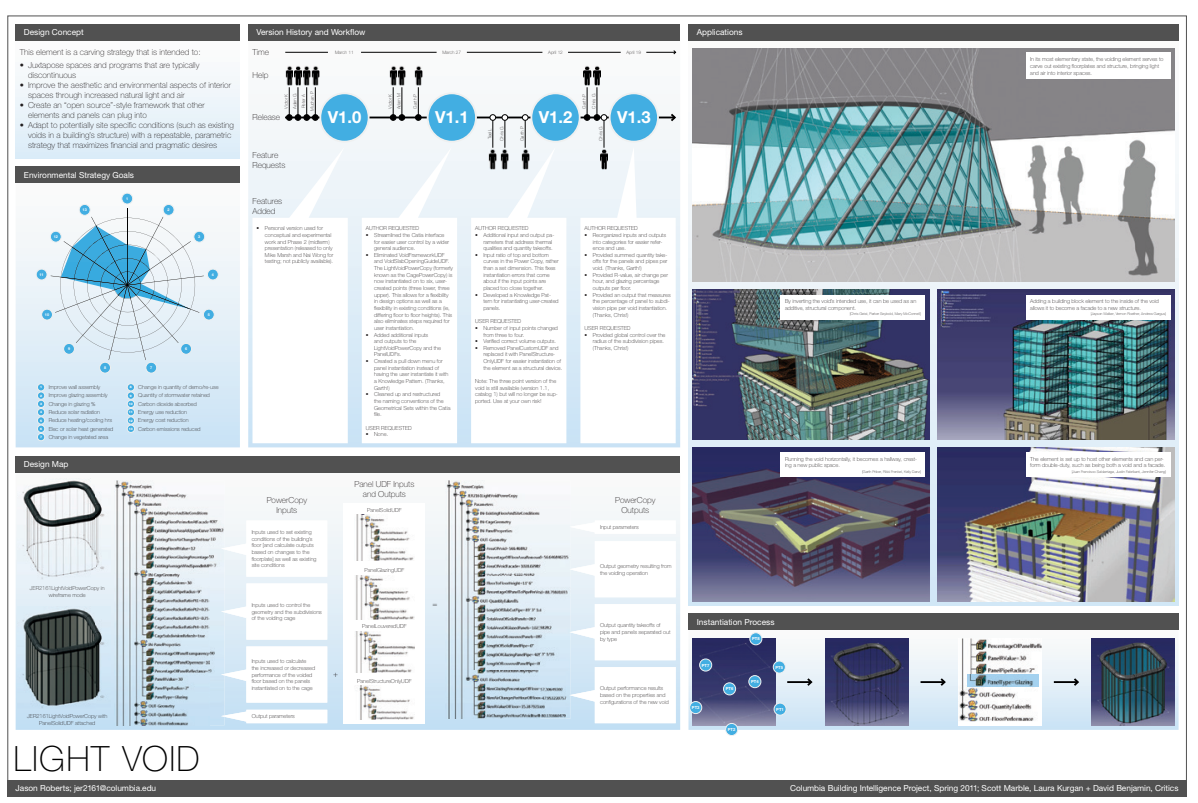

\section{PHASE 2: STRATEGIES}

In the second phase of the studio, students formed into small groups, selected a NYC building type based on research from PlaNYC as a "site" and began developing ideas for a building Strategy. As the student groups were developing concepts, they would search the Element Library for Elements that related to their design intent. As groups would start to test Elements on their sites, they would discover limitations in an Elements functionality that would require updates in order to develop their design. Two important rules of the studio structured this process - the first was that updates to Elements could only be done by the original author; the second was that groups could not use an Element authored by one of its group members. These rules greatly expanded the exchange of Elements and overall sharing of ideas as each student would be working with their own group to develop their Strategy while also working indirectly with several other groups who had selected their Elements for use in the design of their group's Strategy. Following techniques of open source software development, student groups were able to experiment with and suggest specific updates

Figure 3: Sample Element, Juan Francisco Saldarriaga

Figure 4: Jason Roberts

\section{G BIP $=$ STUDIO}
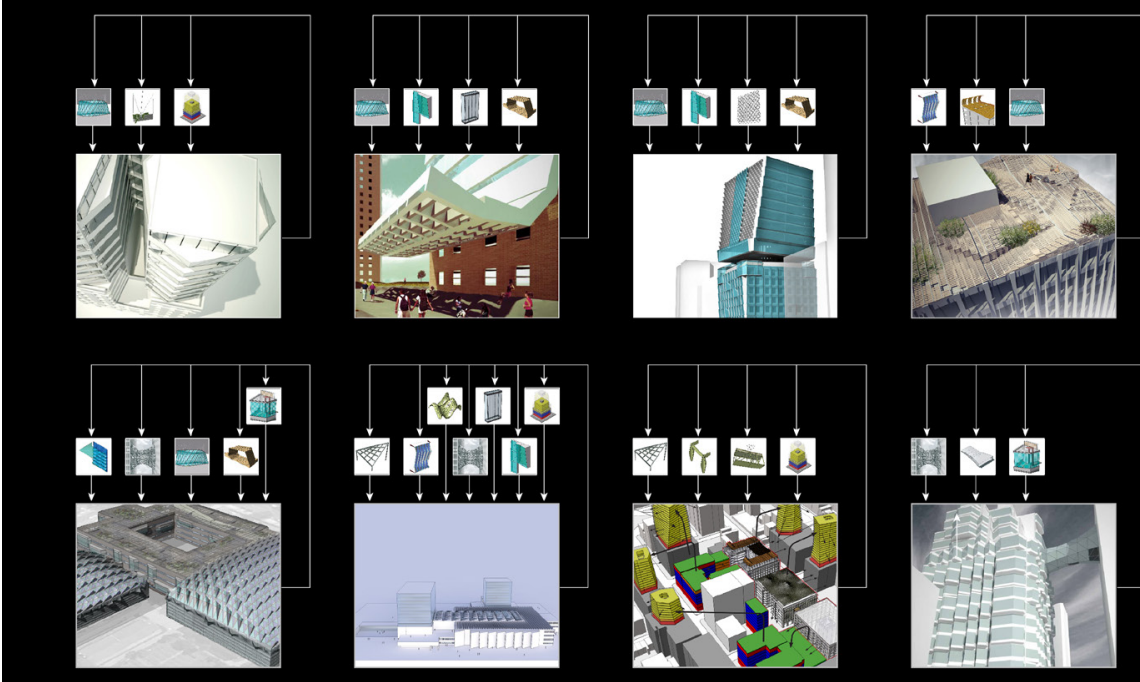

\section{面血妾}

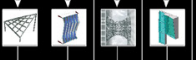

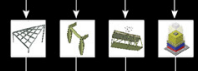
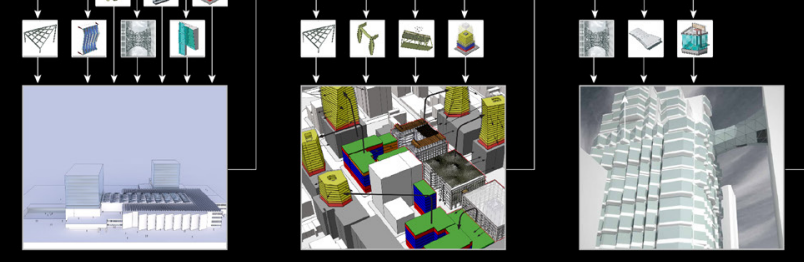
to any Element they might want to use in their Strategy but be required to follow mutually agreeable protocols in getting these updates executed.

The objective of designing Strategies instead of solutions was to encourage students to exploit the parametric capacity of their work so they could be applied to the greatest number of buildings, within their chosen type. For instance, the inputs for the Strategies were variable and could adjust to the specific conditions of different buildings allowing the Strategies to be reusable beyond a single site. With this approach, a limited number of Strategies could be applied to the greatest number of buildings resulting in a more significant impact on the PlaNYC goal of a 30\% reduction in carbon emissions by 2030.

The most successful Strategies were able to get multiple Elements linked together in a fully integrated model where the fewest number of inputs could generate the widest range of design outputs. These outputs were presented as dashboards that included visual images along with numeric and graphic readings of quantitative information about the design. For both Elements and Strategies, results were iterative meaning that there was no single solution but rather multiple iterations based on different inputs.

\section{TRIAL 4: +TWIST}
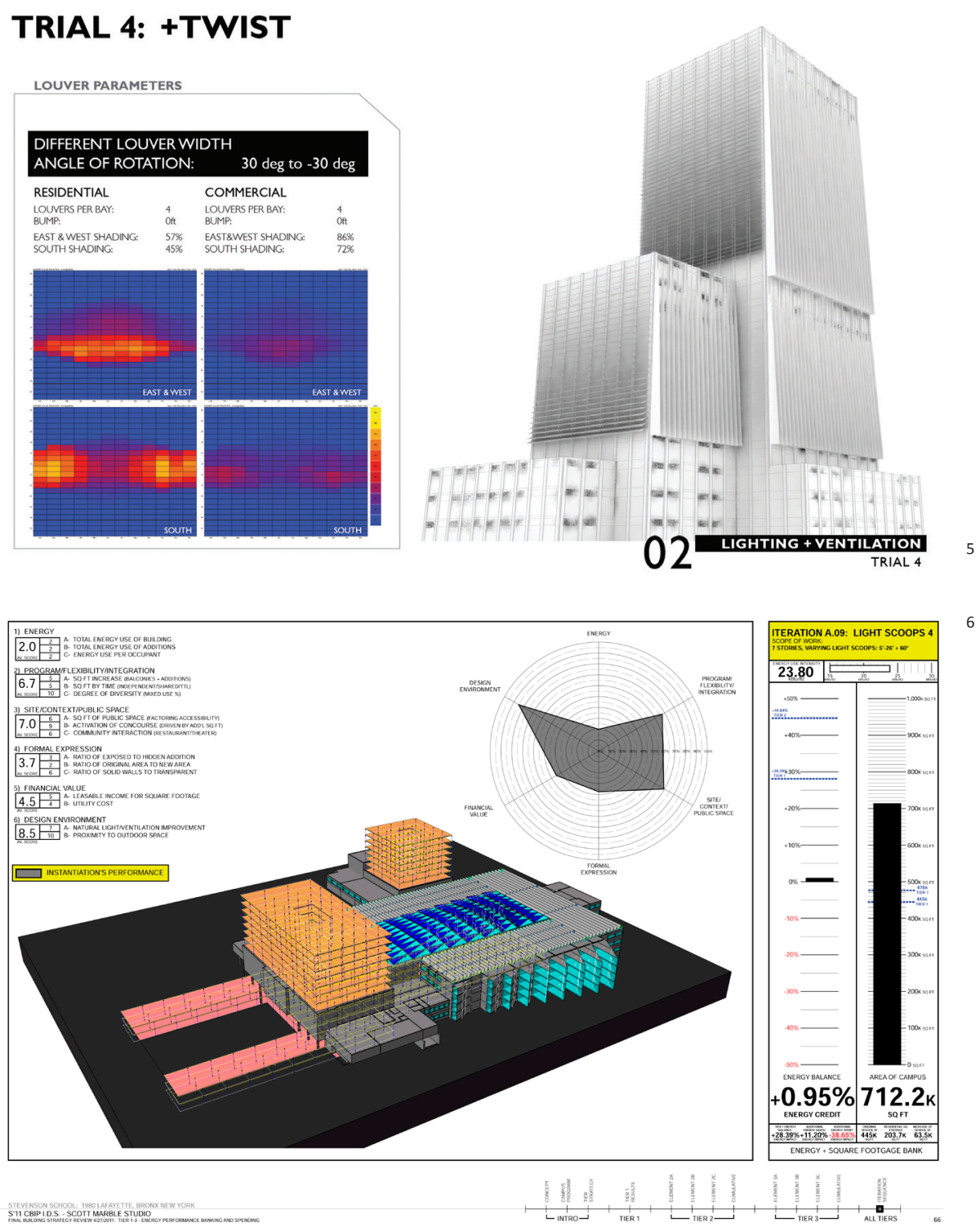

Figure 5: Sample Strategy, Ardeshir Aliaskari, Jennifer Chang, Justin Fabrikant, Juan Francisco Saldarriaga

Figure 6: Dashboard, Jason Roberts, Nai Wong, Michael Marsh, Michael Marvin 


\section{BIP PROJECT CREDITS: C BIP STUDIO DIRECTOR: SCOTT MARBLE}

Design Critics: Scott Marble, David Benjamin, Laura Kurgan, Janette Kim

Industry Consultants: Victor Keto, Gehry Technologies, Software, Optimization; Adam Modesitt, SHoP Architects, Software; Cory Brugger, Morphosis; Software; Neil Meredith, Gehry Technologies, Software; Alexandra Pollack, SOM, Software; Hashim Sulieman, SOM, Software; Neil Thelen, Front, Software; Emilie Hagan, Atelier 10, Energy; Madhev Munshi, Atelier 10, Energy Modeling; Stephen Mignogna, Atelier 10, Energy Modeling; Johathan Schumacher, Thorton Tomsetti, Software, Interoperability; John Cerone, SHoP Construction, Software

Student Teaching Assistants: Jacob Benyi, Caniel Nagy Peter Adams, Adam Gerber, Julie Jira, Muchan Park, Alexis Burson, Chris Geist, Jason Roberts, Garth Priber, Jayson Walker, Joseph Brennan, Kar Bengzon, Christine Nasir, Mia Zinni

C BIP Think Tanks Chair: Phillip Anzalone

The Columbia Building Intelligence Project was generously supported by Oldcastle BuildingEnvelope

Oldcastle BuildingEnvelope Engineering your creativity"

\section{ENDNOTES}

1 Surowiecki, James. 2004. The Wisdom of Crowds: why the many are smarter than the few and how collective wisdom shapes business, economies, societies, and nations. New York: Doubleday, 2004.

2 Raymond, Eric S., 2001. The Cathedral \& the Bazaar; O’Reilly Media

3 Axelrod, Robert, 1984. The Evolution of Cooperation; Basic Books, Inc.
At the conclusion of the 3-year pilot period, the C BIP Library contained over 100 individual Building Elements and over a dozen integrated Building Strategies.

\section{SHARING AS A NEW MODEL OF DESIGN STUDIO}

The technical protocols of the C BIP Studio created a powerful incentive for students to understand the structure of collaborative work. Students quickly realized that the success of their own work relied on the success of their peer's work. This created a unique social dynamic that added unfamiliar factors into their typical design process. For instance, during the Strategy phase of the studio, students would have to manage their time and their aspirations between contributing to their own group Strategy and updating their Elements from feature requests from other Strategy groups. The incentive for focusing on the later was that if their Elements were being used by several groups, their impact on the total studio output would be greater as they would indirectly be part of several groups instead of just one. This was especially the case for students who had very popular Elements. On the other extreme, when an Element was not being used by any group, the author would have to decide whether to put more of their time into their group Strategy or try to revise their Element on their own to be more appealing to users. In general, Elements that were more formally generic and functionally robust were more popular among groups. Some of the most popular Elements over the 3-year period were those that were purely operations. For instance, one of the most popular Elements, Light Void, simply created slab cutouts in existing floor plates, which could be utilized by groups in multiple ways for different programs.

In the second and third year of the studio when students could choose Elements authored by students from previous years as well as those authored by their current studio mates, they tended to use Elements from their current studio. This reinforced the importance of face-to-face exchange when engaging in a creative process like design, even when everything is online. The previous year's Elements, however, did have a cumulative impact on subsequent studios in that students started to be more ambitious with the design of their Elements because they realized that they had to build upon past work and not repeat Elements that already existed in the Library. This awareness of the Elements from previous years indirectly encouraged better design.

\section{CONCLUSION}

Design studio is deeply entrenched in architectural education. Entire curricula revolve around the structure and content of studio and it is the cultural and creative anchor of architectural schools. It is a teaching model that is the envy of educators in its ability to be both structured and open-ended where students learn as much from each other as they do from an instructor. The challenge for educators is how to evolve studio so it not only stays current with, but stays ahead of the profession that it serves. Exploring the full potential of digital design and communication technology and how it can expand the design capacity of our students is one part of addressing this challenge. It is a missed opportunity to casually position digital technology as just tools. Technical skills and design skills are becoming intertwined as part of a complex workflow requiring a new mental agility among designers to move fluidly between qualitative and quantitative thinking. One does not enable the other but rather, they work in tandem.

The challenge for the profession of architecture is whether we will take a back seat in the development of these new workflows and remain on the receiving end of a professional infrastructure that will increasingly set the ground rules for how we practice or alternately whether we become proactive in the design of this infrastructure. This covers both the tools that we use to design and the organizational structure of our professional relationships. How this challenge is met will be determined by how architectural education engages with industry and how bold we are as educators in pursuing curricula that prepares students to lead in this long-overdue change. 